\title{
Secondary Intention Facial Healing: Crucial Guidelines
}

\author{
Jorge Schwember, $\mathrm{MD}^{1 *}$, Gerardo Schwember, MD $^{2}$, Luisa Madrid, MD ${ }^{1}$ \\ ${ }^{1}$ Centro Laser, La Serena, Chile. \\ ${ }^{2}$ Clínica Alemana de Santiago, Chile.
}

*Corresponding Author: Jorge Schwember, Centro Laser, Huanhuali 735, La Serena, 1720412, Chile.

\section{Abstract}

The ideal method for the reparation of facial lesionsis not always obvious. Many times surgeons perform flaps or grafts when secondary healing or granulation in the facial area is a more suitable option. In this article, the authors establish the main guidelines for use of this surgical option based on forty years of experience.

Keywords: wound healing; granulation; skin flap; skin graft.

\section{BODY OF MANUSCRIPT}

When confronted with a facial lesion that requires surgical excision that does not allow direct closure, surgeons often neglect to take into consideration the healing methods of Nature and immediately resort to a flap or graft (Ref. 1,2,3), with the resulting permanent and visible scars that this implies. (Figure 1).

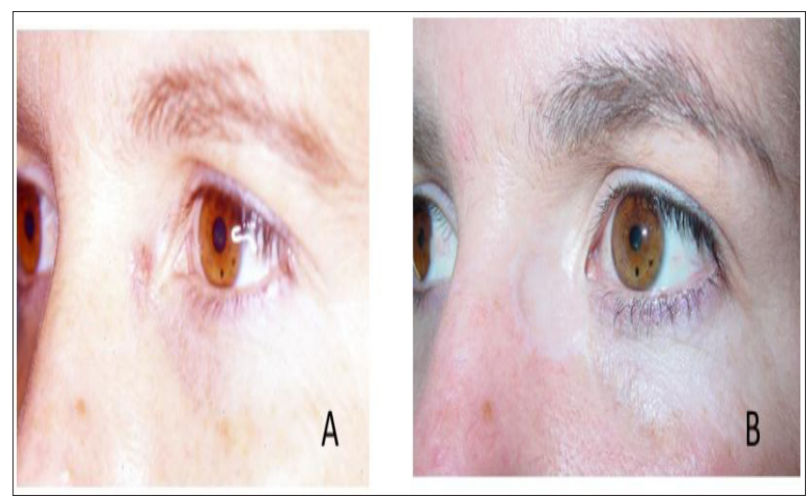

Figure 1. A-Inner canthal basal cell carcinoma. B-Post-skin graft at five years.

Some years ago, the senior author had to perform an orbital exenteration due to a squamous cell carcinoma lesion in a 101-yr-old man. As his medical condition did not allow for a flap repair, the healing was completed by granulation from the skin margin (Figures 2,3). This option has been previously reported in literature (Ref. 4,5,6) and led us to put it into practice on many of our patients in the case of minor facial lesions. The patient shown in Figure 4 had a confirmed clinical diagnosis of basal cell carcinoma; same patient in different stages of healing (Figure 5). Another case presenting pigmented seborrheic keratosis of the lower lid (Figure 6).

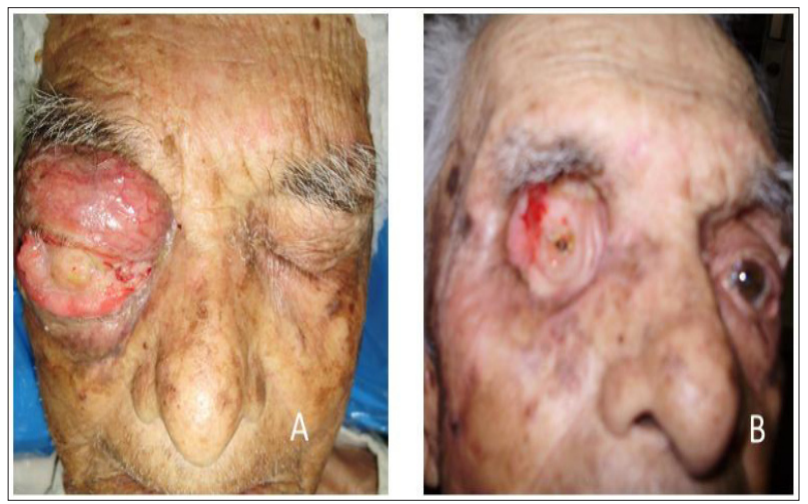

Figure 2. A-Orbital squamous cell carcinoma. B-Post operative at three months.

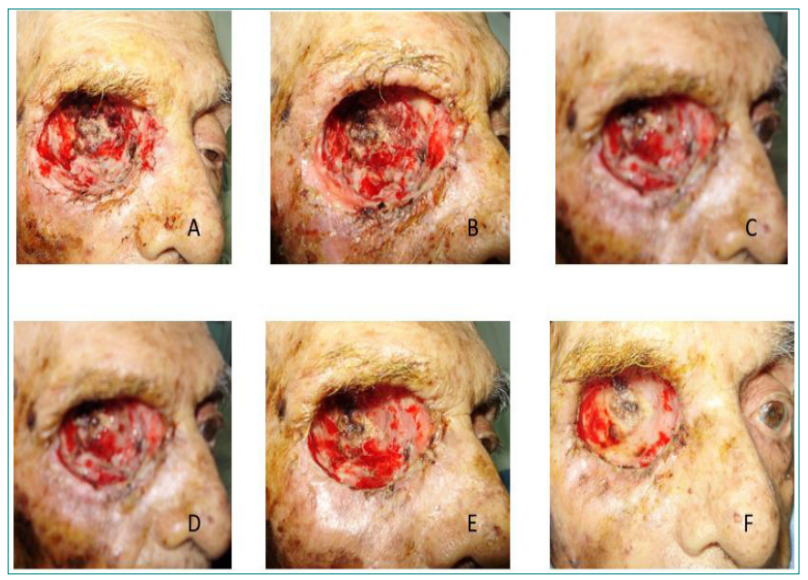

Figure 3. Postoperative at different stages. A-Day five. B-Day ten. C-Day 14. D-Day 17. E-Day 28. F-Day 33 

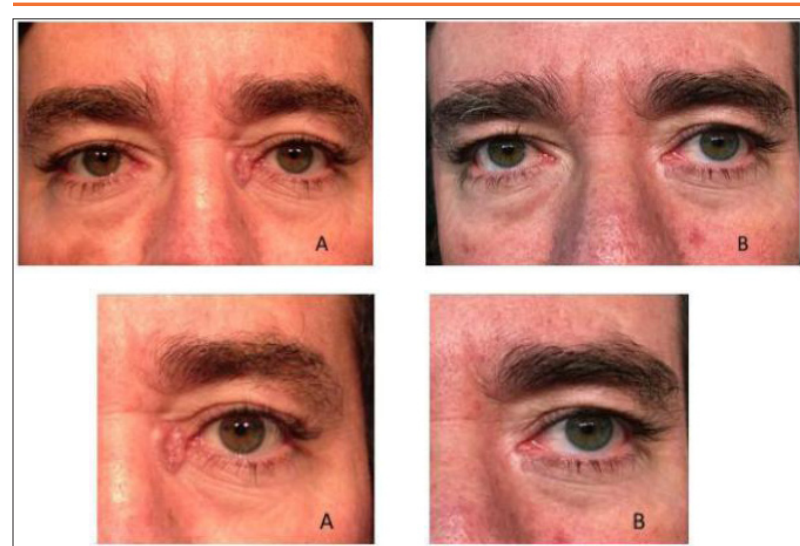

Figure 4. A-Basal cell carcinoma of inner left canthus. $B$-Postoperative at six years, no scarring or epiphora.
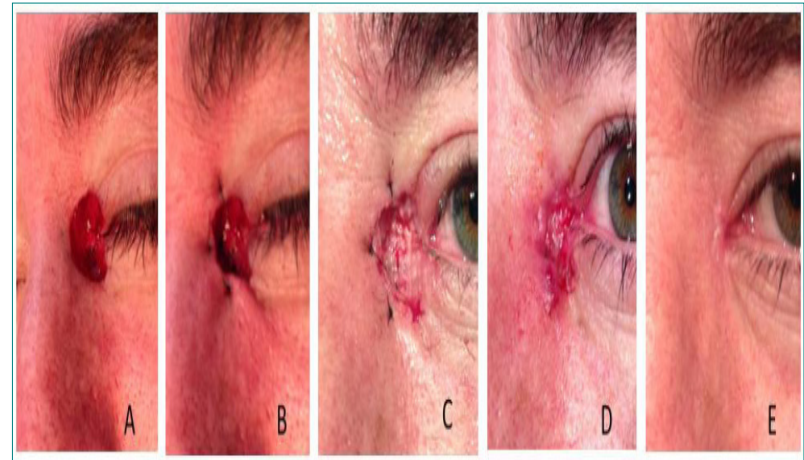

Figure 5. Postoperative at different stages. A-After excision. B-After nylon mattress sutures. C-Day one. D-Day ten. E- Day 40.
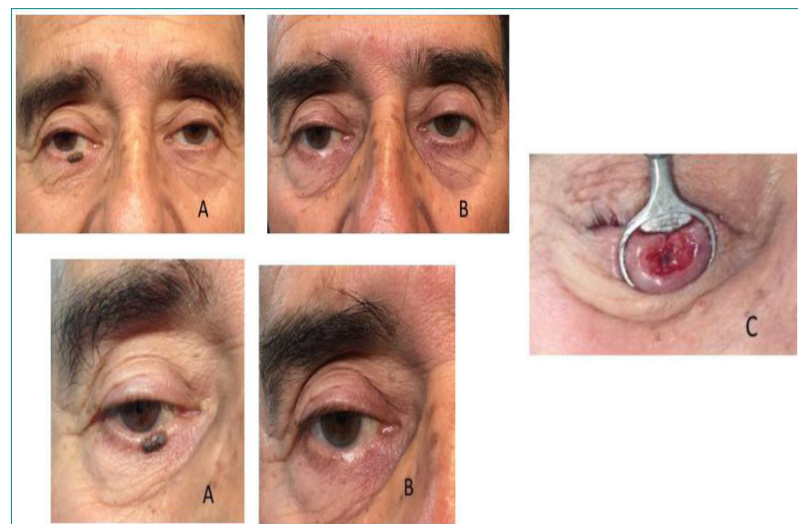

Figure 6. A-Pigmented seborrheic keratosis of the lower lid. B-Postoperative at two years. C-Intraoperative. The tarsus plate provided sufficient support to stabilize the lid margin.

Most of our surgeries are carried out with local anesthesia and mild sedation, with photos taken pre- and post-surgery. Generally, antibiotics are not prescribed. It has been our experience that taking 1 gr daily of ascorbic acid for seven days prior to surgery, can help to prevent bleeding. Patients should be advised to apply a cold compress (a package of frozen vegetables is adequate) to the area on the day following surgery. Follow-up visits are scheduled for the day following surgery to remove the dressing, at 5 days, 10 days and 3 months' time. Iodine is applied on a sterile gauze or cotton ball, and used in light strokes to cleanse the affected area 3 times a day for the first 7 days by the patient or caregiver.

The patient is informed that after a three-month healing period, touch-ups are possible if necessary.

\section{ConClusions}

Secondary healing or granulation is a valid option to repair facial lesions. From our clinical observations, we noted two types of healing by granulation: the first could be referred to as Centripetal, as is shown in Figure 2. Another example of this is noted in Photo refractive Keratectomy (PRK) where the limbal cells provide the new epithelial layer (Ref. 7). The second, as Juxtapositional as can be observed in rinofina (Fig 7) where the healing process is initiated by the remnant pilosebaceous units.

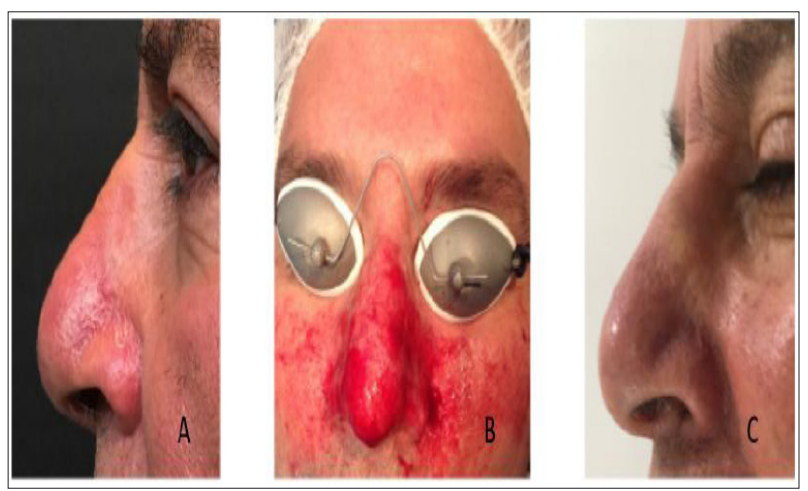

Figure 7. Rinofima treated with Er: YAG laser. A-Preoperative B-Immediately after ablation of 400 um. C-At three months.

\section{GUIDELINES}

- Size: Area of removal not to exceed $2 \mathrm{~cm}^{2}$, with the exception of ablation of the outer layer of skin in rinofima. In the future, bioengineering may allow for increased, controlled cell proliferation and the area of ablation may be extended.

- Location: Preferably over bony prominences such as forehead, glabella, temples, malar areas, nasal root.

- Electrocoagulation: only if necessary provided by bipolar forceps. 
- Mobility: The affected area must be kept as immobile as possible and to ensure this, nylon mattress sutures may be applied in the early stages. It is for this reason that some soft areas such as nasal wings, lips and lids are not suitable for this procedure

- Design: This option is more adequate for circular or quadrilateral shapes.

- Patient should be non-smoker.

- This approach is not suitable for patients that tend to develop hypertrophic or keloid scars.

- Sun exposure: avoid at least during the first three months.

Funding Sources: The authors received no financial support for the research, authorship, and/or publication of this article.

Conflicts of Interest: The authors declared no potential conflicts of interest with respect to the research, authorship, and/or publication of this article.

Patient Consent: Patients provided written consent for the use of their images.

\section{REFERENCES}

[1] Shan Baker (2014). Local Flaps in Facial Reconstruction. $3^{\text {rd }}$ Edition. 2014 Saunders

[2] Vera L (2015). Colgajos cutaneos para la reconstrucción del área nasal invadida por carcinomas basocelulares. Rev Med La Paz 21:46-51

[3] Schwember J, Hoppmann R (1981). Reconstruccion nasal. Rev Soc Chil Cir Plast y Repar 2: 18-23

[4] Putterman AM (1986). Orbital Exenteration with Spontaneous Granulation. Arch Ophthalmol 104 (1): $139-140$

[5] Pacheco, P (2016). Advances in Eye Surgery: 57. http:dx doi org/10.5772/59216

[6] De Almeida G, Mussi N, Fernandes RL, Tagliarini JV, Alencar ME, Artioli S (2016). Orbital Exenteration: a series of cases. Rev Bras Oftalmol 75: 452-455

[7] Tomás-Juan J, Murueta-Goyena Larrañaga A, Hanneken L. Corneal Regeneration After Photorefractive Keratectomy: A Review. J Optom. (2015) Jul-Sep;8(3):149-69. [PMC free article] [PubMed]

Citation: Jorge Schwember, Gerardo Schwember, Luisa Madrid. Secondary Intention Facial Healing: Crucial Guidelines. Archives of Dermatology and Skin Care. 2020; 3(2): 06-08.

Copyright: (C) 2020 Jorge Schwember, Gerardo Schwember, Luisa Madrid. This is an open access article distributed under the Creative Commons Attribution License, which permits unrestricted use, distribution, and reproduction in any medium, provided the original work is properly cited. 